\title{
The Crystal Structure of Rubidium and Potassium Dibutyldithiocarbamates
}

\author{
ANDERS WAHLBERG
}

Institute of Chemistry, University of Uppsala, Box 531, S-751 21 Uppsala 1, Sweden

The crystal structures of the title compounds were determined from three-dimensional diffractometer $X$-ray data. Crystals of the isomorphous compounds are monoclinic, space group $P 2, c, Z=4 . a=16.029(1) \AA, b=6.487(1)$ $\AA, c=13.383(1) \AA, \beta=106.22(1)^{\circ}, R=0.078$ for $\mathrm{RbS}_{2} \mathrm{CN}\left(\mathrm{C}_{4} \mathrm{H}_{0}\right)_{2}$ and $a=16.085(3) \AA, b=6.361(1)$ $\AA, c=13.207(2) \AA, \beta=106.12(1)^{\circ}, R=0.121$ for $\mathrm{KS}_{2} \mathrm{CN}\left(\mathrm{C}_{4} \mathrm{H}_{9}\right)_{2}$. The metal atoms are coordinated to six sulfur atoms with mean distances $\mathrm{Rb}-\mathrm{S}=3.43 \AA$ and $\mathrm{K}-\mathrm{S}=3.33 \AA$. The compounds are layer polymers, the layers being held together by van der Waals forces. The structures are closely related to the cesium and thallium dibutyldithiocarbamates.

Cesium dimethyldithiocarbamate ${ }^{1}$ is a chain polymer with metal-sulfur interactions between the chains. The metal atom is eight. coordinated. Cesium dibutyldithiocarbamate 8 is a layer polymer with six-coordinated cesium atoms. The coordination number for thallium in thallium(I) dithiocarbamates lies between five and seven. Dimers are linked to form chain or layer polymers. The crystal structures formed are very sensitive to the size and shape of the alkyl substituents. Related effects are expected in the alkali dithiocarbamates with varying radius of the coordinating cation. The crystal structure of rubidium dibutyldithiocarbamate is expected $\left(r_{\mathrm{Rb}^{+}} \approx r_{\mathrm{Tl}^{+}}\right)$to resemble those of cesium and thallium, ${ }^{3}$ which are very similar.

\section{EXPERIMENTAL}

Rubidium dibutyldithioc a r b a mate

Crystal preparations. The compound was prepared as described by Uhlin. ${ }^{4}$ The solid hydroscopic product was dried in vacuo and recrystallized from benzene. The crystals developed as pale orange-yellow flakes elongated along [010] and with faces (100). The density was measured by flotation in mixtures of $\mathrm{CCl}_{4}$ and $\mathrm{C}_{6} \mathrm{H}_{5} \mathrm{Cl}$. Accurate unit cell dimensions were obtained from a powder photograph taken on an IRDAB XCD 700 camera using $\mathrm{Cr} K \alpha_{1}$ radiation with silicon $(a=5.43054 \AA)$ as an internal standard. 89 observed $\theta$-values were used in the least-squares refinements of the cell parameters.

Crystal data. Monoclinic crystal system, space group $P 2_{1} / c, Z=4, a=16.029(1) \AA, b=6.487(1)$ $\AA, c=13.383(1) \AA, \beta=106.22(1)^{\circ}, V=1336.2$ $\AA^{3}, \quad D_{0}=1.44(1) \mathrm{g} \mathrm{cm}^{-8}, D_{\mathrm{x}}=1.441 \mathrm{~g} \mathrm{~cm}^{-3}$, m.p.o $=171-175{ }^{\circ} \mathrm{C}, \quad$ m.p.1it ${ }^{4}=148-150{ }^{\circ} \mathrm{C}$, $\mu(\mathrm{MoK} \alpha)=41.9 \mathrm{~cm}^{-1}$.

Intensity data. The intensity data were collected at room temperature on a Stoe-Philips four-circle PDP 8/I computer controlled diffractometer with a graphite monochromator using $M o K \alpha$ radiation and an $\omega-2 \theta$ scan technique. The two crystals used were mounted on glass fibres and were protected from air by thin-walled glass capillaries. 436 and 498 intensities were collected on the first $(0.048 \times 0.140 \times$ $\left.0.098 \mathrm{~mm}^{3}\right)$ and second $(0.070 \times 0.356 \times 0.056$ $\mathrm{mm}^{3}$ ) crystals, respectively, $\sin \theta / \lambda \leq 0.40$. The standard reflections were $\overline{413}, 2 \overline{2} 0$, and 006 , and 040,004 , and 500. The transmission factor varied from 0.66 to 0.83 and 0.64 to 0.81 . The intensities were measured for $176 \mathrm{~s}$ (five re. flections were measured for 88 s) and the back. grounds for $2 \times 25 \mathrm{~s}$. The orientations of the crystals were repeatedly checked. The standard reflections were measured at intervals of 40 reflections. The intensities were corrected for crystal decomposition by a formula developed from studies of the decrease of the standard reflections (some strong reflections first increased, then decreased). The crystals were used until the intensities of the standard reflections were reduced by ca $20 \%$. The reflections $100,001, \overline{101}$, and 101 were absorbed in the primary beam stop. Corrections for 
Table 1. Atomic coordinates and thermal parameters for rubidium dibutyldithiocarbamate. The anisotropic temperature factor is defined as $\exp \left(-\beta_{11} h^{2}-\beta_{22} k^{2}-\beta_{33} l^{2}-2 \beta_{12} h k-2 \beta_{13} h l-2 \beta_{23} k l\right)$.

\begin{tabular}{|c|c|c|c|c|c|c|}
\hline Atom & $x$ & $y$ & $z$ & $B \AA^{2}$ & & \\
\hline $\mathrm{Rb}$ & $0.0006(1)$ & $0.2090(3)$ & $0.1100(1)$ & & & \\
\hline S1 & $0.1754(3)$ & $-0.0443(8)$ & $0.0722(4)$ & & & \\
\hline S2 & $0.0613(3)$ & $-0.3013(7)$ & $0.1606(4)$ & & & \\
\hline $\mathrm{C}$ & $0.164(1)$ & $-0.232(3)$ & $0.159(1)$ & $4.3(4)$ & & \\
\hline $\mathrm{N}$ & $0.234(1)$ & $-0.308(2)$ & $0.223(1)$ & $5.4(4)$ & & \\
\hline Cl1 & $0.323(1)$ & $-0.240(3)$ & $0.228(2)$ & $6.8(5)$ & & \\
\hline $\mathrm{C} 12$ & $0.357(2)$ & $-0.344(4)$ & $0.146(2)$ & $8.8(7)$ & & \\
\hline Cl3 & $0.444(2)$ & $-0.239(5)$ & $0.142(3)$ & $11.9(9)$ & & \\
\hline C14 & - & - & - & - & - & \\
\hline C21 & $0.231(1)$ & $-0.449(4)$ & $0.317(2)$ & $7.6(6)$ & & \\
\hline C22 & $0.266(2)$ & $-0.654(4)$ & $0.301(2)$ & $8.3(6)$ & & \\
\hline $\mathrm{C} 23$ & $0.265(1)$ & $-0.792(3)$ & $0.401(2)$ & $7.2(6)$ & & \\
\hline $\mathrm{C} 24$ & $0.174(1)$ & $-0.881(4)$ & $0.387(2)$ & $6.9(5)$ & & . \\
\hline Atom & $\beta_{11}$ & $\beta_{22}$ & $\beta_{33}$ & $\beta_{12}$ & $\beta_{13}$ & $\beta_{23}$ \\
\hline $\mathrm{Rb}$ & $0.0072(2)$ & $0.0219(12)$ & $0.0054(3)$ & $0.0004(2)$ & $0.0019(1)$ & $-0.0009(2)$ \\
\hline S1 & $0.0064(4)$ & $0.0325(20)$ & $0.0070(5)$ & $-0.0026(6)$ & $0.0022(3)$ & $0.0019(7)$ \\
\hline S2 & $0.0061(4)$ & $0.0260(21)$ & $0.0068(5)$ & $-0.0009(6)$ & $0.0022(3)$ & $0.0010(6)$ \\
\hline
\end{tabular}

background, Lorentz and polarization effects (including monochromator polarization) and absorption were applied before the data set was reduced, giving 716 independent reflections.

Structure determination and refinements. The metal atom positions were obtained from the three-dimensional Patterson function. The other non-hydrogen atoms, except one terminal carbon atom, C14, were located in difference Fourier syntheses. Scale factors and positional and isotropic thermal parameters were then refined by full matrix least-squares. Attempts were made to include the remaining carbon atom in the refinements, but the large thermal parameters and the unsatisfactory bond distances and angles showed that this atom was disordered. All reflections were included in the final refinement of 65 parameters (anisotropic thermal parameters for the metal and sulfur atoms). The final shifts were less than a tenth of the standard deviations. Resulting positional and thermal parameters are collected in Table 1. A list of squares of observed and calculated structure amplitudes is available on request. $R\left(F^{2}\right)=\sum \| F_{0}^{2}|-| F_{c}^{2}|| / \sum\left|F_{o}^{2}\right|=0.132$, $R_{\mathrm{w}}\left(F^{2}\right)=\left(\sum w\left(\left|F_{\mathrm{o}}^{2}\right|-\left|F_{\mathrm{c}}^{2}\right|\right)^{2} / \sum w\left|F_{\mathrm{o}}^{4}\right|\right)^{\frac{1}{3}}=0.183$, $R(F)=0.078$. The expression $w\left(\left|F_{\mathrm{o}}^{2}\right|-\left|F_{\mathrm{c}}{ }^{2}\right|\right)^{2}$ was minimized in the least-squares refinements with the weights $w^{-1}=\left(1.20 \sigma_{\mathrm{c}}\left(F^{2}\right)\right)^{2}+\left(0.08\left|F_{0}{ }^{2}\right|\right)^{2}$ $=\sigma\left(F^{2}\right)^{2}$. Scattering factors ${ }^{5}$ were used for the neutral atoms. Corrections for anomalous dispersion ${ }^{6}$ were applied for the metal and sulfur atoms. The highest electron density maxima in a difference Fourier synthesis following the refinements were located at three positions reasonable for $\mathrm{Cl} 4\left(0.19,0.16\right.$, and 0.11 e $\left.\AA^{-3}\right)$. The remaining electron density was less than
0.10 e $\AA^{-3}$. The calculations 7 were performed on the IBM 370/155 computer in Uppsala.

Potassium dibutyldithioc a r b a mate

The experiments were generally performed as for the rubidium compound. The crystals resembled those of the rubidium compound, but the flakes were only a few $\mu$ m thick. The cell parameters were obtained from 60 -angles.

Crystal data, monoclinic crystal system, space group $P 2_{1} / c, Z=4, a=16.085(3) \AA, b=$ 6.361(1) $\AA, c=13.207(2) \AA, \beta=106.12(1)^{\circ}, V=$ $1298.3 \AA^{3}, D_{\mathrm{o}}=1.25(1) \mathrm{g} \mathrm{cm}-D_{\mathrm{x}}=1.246 \mathrm{~g}$

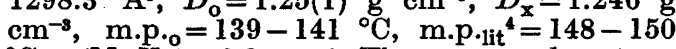
${ }^{\circ} \mathrm{C}, \mu(\mathrm{MoK} \alpha)=6.8 \mathrm{~cm}^{-1}$. There were almost no intensities on Weissenberg films at $\sin \theta / \lambda<$ 0.30 . No improvement was obtained by cooling to the temperature of boiling nitrogen.

388 intensities were collected from a crystal of dimensions $0.016 \times 0.356 \times 0.182 \mathrm{~mm}^{3}, \sin \theta /$ $\lambda \leq 0.29$. The standard reflections were 004 , 500 , and 020 , and the transmission factor varied from 0.84 to 0.99 . The intensities were measured for $69 \mathrm{~s}$ and the backgrounds for $2 \times 20 \mathrm{~s}$. At the end of the experiment the intensities of the standard reflections had been reduced by $c a .50 \%$.

Positional parameters from rubidium dibutyldithiocarbamate were refined to fit the potassium dibutyldithiocarbamate data. The refinement was based on $F$, and 175 reflections $\left(\left|F_{\mathrm{o}}\right|>2 \sigma, \quad 0.25<\left|F_{\mathrm{o}}\right| /\left|F_{\mathrm{c}}\right|<4.0\right)$ were included in the final cycles to refine 49 parameters. Without introduction of anisotropic thermal param-

Acta Chem. Scand. A 30 (1976) No. 8 
Table 2. Atomic coordinates and thermal parameters for potassium dibutyldithiocarbamate.

\begin{tabular}{lllll}
\hline Atom & $x$ & $y$ & $z$ & $B \AA^{2}$ \\
\hline K & $0.000(1)$ & $0.201(3)$ & $0.110(1)$ & $6.2(8)$ \\
S1 & $0.167(1)$ & $-0.041(4)$ & $0.066(2)$ & $6.5(10)$ \\
S2 & $0.056(1)$ & $-0.307(4)$ & $0.160(2)$ & $5.8(9)$ \\
C & $0.151(6)$ & $-0.204(16)$ & $0.156(7)$ & $9(3)$ \\
N & $0.226(5)$ & $-0.316(10)$ & $0.221(5)$ & $6(2)$ \\
C11 & $0.318(4)$ & $-0.236(11)$ & $0.225(5)$ & $3(2)$ \\
C12 & $0.354(4)$ & $-0.363(11)$ & $0.127(5)$ & $4(2)$ \\
C13 & $0.455(5)$ & $-0.236(14)$ & $0.115(5)$ & $10(3)$ \\
C21 & $-0.226(6)$ & $-0.423(18)$ & $0.325(8)$ & $-12(4)$ \\
C22 & $0.273(5)$ & $-0.644(15)$ & $0.307(7)$ & $8(3)$ \\
C23 & $0.271(4)$ & $-0.798(11)$ & $0.409(5)$ & $4(2)$ \\
C24 & $0.169(5)$ & $-0.895(11)$ & $0.387(5)$ & $5(3)$ \\
\hline
\end{tabular}

eters the refinement converged at $R(F)=0.121$ and $R_{\mathrm{w}}(F)=0.146$. The weights were $w^{-1}=$ $\left(1.50 \sigma_{\mathrm{c}}\left(F^{\prime}\right)\right)^{2}+\left(0.09\left|F_{\mathrm{o}}\right|\right)^{2}$. Again the atom Cl4 was found to be disordered. Positional and thermal parameters are collected in Table 2. A list of observed and calculated structure amplitudes is available on request.

\section{RESULTS AND DISCUSSION}

General. The crystal structures of the two compounds are very similar. Ionic bonds link the metal atoms and ligands in layers parallel with the bc-plane, Fig. 1. The layers are connected by van der Waals forces, the main contacts being between alkyl groups.

The dimeric unit. A plane through the metal and S2 sulfur atoms in the centrosymmetric dimer in Fig. 2 is approximately parallel to the $b c$-plane. The dimer is similar to those found in the dithiocarbamates of monovalent thallium, but it interacts more strongly with neighbouring dimers.

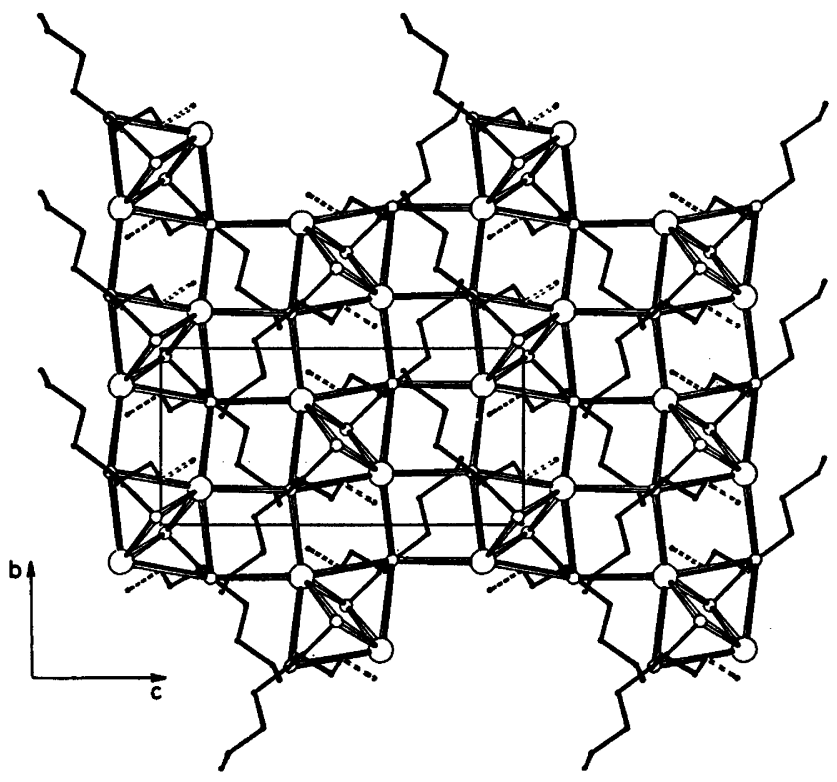

Fig. 1. The layer. 


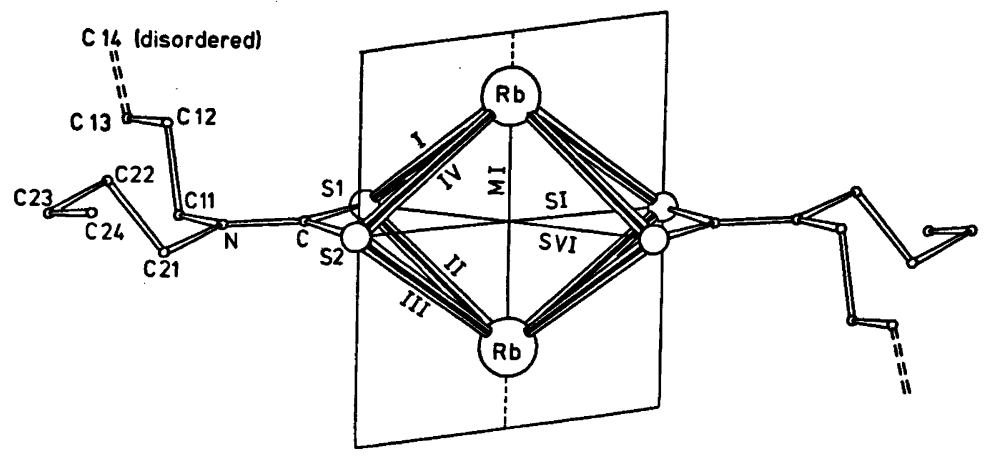

Fig. 2. The centrosymmetric dimeric unit.

The ligand. The atoms in the dibutyldithiocarbamate ligand are defined in Fig. 2. Cl4 is given a position with normal distances and angles (dashed bonds). The ligand appears normal. Distances and angles are collected in Table 3. The S1-S2-C-N-C11-C21 part of the ligand is planar within experimental error, except C21, which is displaced from the

Table 3. Interatomic distances $(\AA)$ and angles $\left.{ }^{\circ}\right)$ for the dibutyldithiocarbamate ligand.

\begin{tabular}{lll}
\hline & $\begin{array}{l}\text { Rubidium } \\
\text { dibutyldithio- } \\
\text { carbamate }\end{array}$ & $\begin{array}{l}\text { Potassium } \\
\text { dibutyldithio- } \\
\text { carbamate }\end{array}$ \\
\hline Distance & & \\
S1-S2 & $2.96(1)$ & $2.96(3)$ \\
S1-C & $1.73(2)$ & $1.64(10)$ \\
S2-C & $1.71(2)$ & $1.68(10)$ \\
C-N & $1.31(2)$ & $1.46(12)$ \\
N-C11 & $1.47(3)$ & $1.55(10)$ \\
N-C21 & $1.57(3)$ & $1.53(12)$ \\
C11-C12 & $1.52(3)$ & $1.76(10)$ \\
C12-C13 & $1.57(4)$ & $1.86(10)$ \\
C21-C22 & $1.49(3)$ & $1.63(14)$ \\
C22-C23 & $1.62(3)$ & $1.67(11)$ \\
C23-C24 & $1.53(3)$ & $1.69(10)$ \\
Angle & & \\
S1-C-S2 & $119(1)$ & $126(6)$ \\
S1-C-N & $118(1)$ & $118(7)$ \\
S2-C-N & $123(1)$ & $114(7)$ \\
C-N-C11 & $124(2)$ & $119(6)$ \\
C-N-C21 & $122(2)$ & $123(7)$ \\
C11-N-C21 & $113(2)$ & $110(6)$ \\
N-C11-C12 & $108(2)$ & $109(5)$ \\
C11-C12-C13 & $106(2)$ & $110(5)$ \\
N-C21-C22 & $110(2)$ & $98(7)$ \\
C21-C22-C23 & $112(2)$ & $106(6)$ \\
C22-C23-C24 & $109(2)$ & $108(5)$ \\
\hline
\end{tabular}

least-squares plane by $0.14(3) \AA$ in the rubidium compound and by $0.30(11) \AA$ in the potas. sium compound. The figures show that the two butyl groups are located on the same side of the dithiocarbamate plane. It should be noted that the substituents are situated on both sides of the plane in the compounds of cesium and thallium.

Metal-sulfur coordination. The metal atoms are coordinated to six sulfur atoms in four ligands. The average metal - sulfur distance is 3.43 and $3.33 \AA$ in the rubidium and potassium compounds, respectively. Subtraction of Shan-

Table 4. Metal-sulfur, metal-metal and sulfursulfur distances $(\AA)$ less than $6 \AA$.

\begin{tabular}{lll}
\hline Distance & $\begin{array}{l}\text { Rubidium } \\
\text { dibutyldithio- } \\
\text { carbamate }\end{array}$ & $\begin{array}{l}\text { Potassium } \\
\text { dibutyldithio- } \\
\text { carbamate }\end{array}$ \\
\hline & & \\
I, metal-S1 & $3.347(6)$ & $3.19(3)$ \\
II, metal-S1 & $3.405(6)$ & $3.28(3)$ \\
III, metal-S2 & $3.463(5)$ & $3.37(3)$ \\
IV, metal-S2 & $3.529(5)$ & $3.49(3)$ \\
V, metal-S2 & $3.336(5)$ & $3.27(3)$ \\
VI, metal-S2 & $3.480(5)$ & $3.40(3)$ \\
MI, metal-metal & $3.998(4)$ & $3.87(4)$ \\
MII, metal-metal & $4.784(4)$ & $4.80(4)$ \\
MII, metal-metal & $4.961(4)$ & $4.87(4)$ \\
SI, S2-S2 & $5.74(1)$ & $5.66(3)$ \\
SII, S2-S2 & $4.93(1)$ & $4.77(3)$ \\
SIII, S2-S2 & $4.77(1)$ & $4.63(3)$ \\
SIV, S1-S2 & $2.96(1)$ & $2.96(3)$ \\
SV, S1-S2 & $4.74(1)$ & $4.55(3)$ \\
SVI, S1-S1 & $5.44(1)$ & $5.18(3)$ \\
S1-S2 & $5.96(1)$ & $5.74(3)$ \\
S1-S2 & $5.40(1)$ & $5.26(3)$ \\
S1-S2 & $5.39(1)$ & $5.26(3)$ \\
\hline
\end{tabular}

Acta Chem. Scand. A 30 (1976) No. 8 


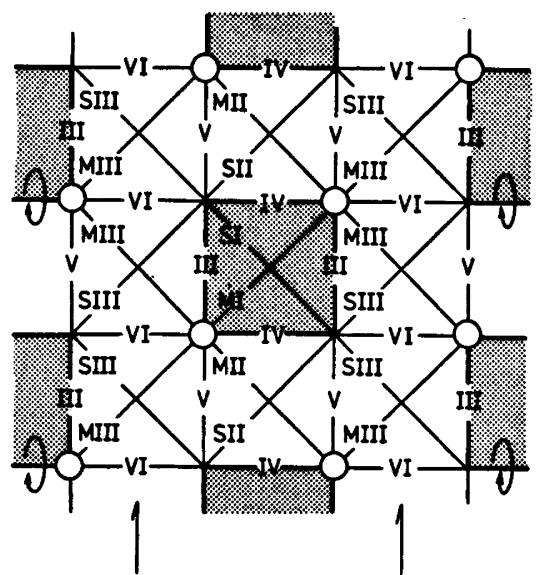

Fig. 3. A schematical representation of the layer.

non and Prewitt effective metal ionic radii ${ }^{8}$ from the average distances gives a radius of 1.94 and $1.95 \AA$ for sulfur in the ionic dithiocarbamate ligand. The radius is longer than the Pauling ionic radius for $\mathrm{S}^{2-}(1.84 \AA)$, but agrees with those derived from cesium dibutyldithiocarbamate (1.92 $\AA$ ) and cesium dimethyldithiocarbamate (ca. 2.00 $\AA$ ). Table 4 shows that the two-coordinated sulfur atom $S 1$ has shorter average metal - sulfur distances (I, II) than the four-coordinated atom S2 (III - VI). The two shortest metal-sulfur bonds are situated within (I) and outside (V) the dimer, the longest one (IV) being inside. Thus, the structure is a layer polymer.

Potassium is coordinated by six sulfur atoms at the average distance $3.32 \AA$ and by one oxygen atom in the potassium xanthate $\mathrm{KS}_{2} \mathrm{COC}_{2} \mathrm{H}_{5}{ }^{\circ}$ The mean distance is $3.37 \AA$ for another potassium atom, which coordinates to an additional sulfur atom. In the dithioacetate $\mathrm{KS}_{2} \mathrm{CCH}_{\mathbf{3}}{ }^{10}$ the average $\mathrm{K}-\mathrm{S}$ distance for the eight-coordinated metal atom is $3.40 \AA$. In the dithioformate $\mathrm{KS}_{2} \mathbf{C H}{ }^{11}$ two independent potassium atoms are each surrounded by eight equivalent sulfur atoms at distances of $\mathbf{3 . 3 5 2}$ and $3.576 \AA$.

The layer. Fig. 3 shows how a dimer (shaded) with a centre of symmetry at $0,0,0$ is linked to its neighbours. Two dimers at $0, \pm 1,0$ are each linked by two metal-sulfur bonds, and four at $0, \pm \frac{1}{2}, \pm \frac{1}{2}$ by one bond. By rotations of the shaded area (as indicated in Fig. 3) in every second column, the linkage of four dimers, each by two metal - sulfur bonds, to a central unit is obtained. This layer arrangement is found in the dibutyldithiocarbamates of cesium and thallium.

Acknowledgements. I wish to express by gratitude to Professor Ivar Olovsson for his interest in my work and for the facilities put at my disposal. I am indebted to Dr. Rolf Hesse and Dr. Per Jennische for stimulating discus. sions. This work has been supported by grants from the Swedish Natural Science Council.

\section{REFERENCES}

1. Wahlberg, A. Acta Chem. Scand. A 30 (1976) 433.

2. Aava, U. and Hesse, R. Ark. Kemi 30 (1968) 149.

3. Elfwing, E., Anacker-Eickhoff, H., Jennische, P. and Hesse, R. Acta Chem. Scand. A 30 (1976) 335.

4. Uhlin, A. and Akerström, S. Acta Chem. Scand. 25 (1971) 393.

5. Hanson, H. P., Herman, F., Lea, J. D. and Skillman, S. Acta Crystallogr. 17 (1964) 1040.

6. Cromer, O. T. Acta Crystallogr. 18 (1965) 17.

7. Lundgren, J.-O. (1974) Crystallographic Computer Programs UUIC-B13-4-01, Inst. of Chemistry, Univ. of Uppsala, Sweden.

8. Shannon, R. D. and Prewitt, C. T. Acta Crystallogr. B 25 (1969) 925.

9. Mazzi, F. and Tadini, C. Z. Kristallogr. 118 (1963) 378.

10. Borel, M. M. and Ledsert, M. Z. Anorg. Allg. Chem. 415 (1975) 285.

11. Engler, R., Kiel, G. and Gattow, G. $Z$. Anorg. Allg. Chem. 404 (1974) 71.

Received February 24, 1976. 